\title{
El Te Deum Evangélico en Chile, cuando la legitimidad religiosa y política es mutua
}

\author{
Luis Orellana Urtubia (https://orcid.org/ 0000-0001-7411-2126)' \\ Universidad Arturo Prat, Tarapacá, Chile.
}

Evguenia Fediakova (https://orcid.org/ 0000-0003-1481-8586)" Universidad de Santiago de Chile, Santiago, Chile.

Resumen: Este artículo busca dilucidar los intereses tanto de los actores políticos como de los agentes religiosos que han hecho posible que el Te Deum Evangélico sea parte de la cultura religiosa y política en Chile. Mediante un examen socio histórico se explica cómo los Te Deum evangélicos en Chile se convirtieron en el símbolo de la salida de cristianos no católicos a la participación política y fueron canal de legitimación y elevación de estatus de una minoría religiosa. Desde lo metodológico, el abordaje fue a partir del nuevo rol de los evangélicos a nivel público y nacional, analizado desde dos perspectivas teóricas: la desprivatización de las religiones en el mundo moderno de José Casanova y la teoría de campo religioso de Pierre Bourdieu. La primera parte, se refiere a la evolución histórico-social de los evangélicos en Chile como una minoría "invisible"; la segunda, demuestra el acercamiento entre los evangélicos y el gobierno de Pinochet a través de los Te Deum; en la tercera, se examinan las relaciones entre los organizadores de los Te Deum y como este fue legitimado por los gobiernos democráticos. Para acceder a la versión de distintos actores entre 1973-1991 acudimos a fuentes primarias como las publicaciones de la prensa escrita, visual, revista especializadas, documentos y libros.

Palabras claves: Te Deum. Evangélico. Chile. Pastores. Religión. Política.

\section{The Evangelical Te Deum in Chile, when religious and political legitimacy is mutual}

Abstract: This article seeks to clarify the interests of both political and religious agents that have made possible for the Evangelical Te Deum to be part of the religious and political culture in Chile. Through a social-historical examination, it is explained how the evangelical Te Deum in Chile became the symbol of the exit of non-Catholic Christians to political participation and were a channel of legitimation and elevation of status of a religious minority. From a methodological point of view, the approach was based on the new role of evangelical people at the public and national levels, analyzed from two theoretical perspectives: the deprivatization of religions in the modern world by José Casanova and the religious field theory of Pierre Bourdieu. The first part refers to the historical-social evolution of evangelical people in Chile as an "invisible" minority; the second demonstrates the rapprochement between evangelical people and the Pinochet government through the Te Deum; in the third, the relationship between the organizers of the Te Deum and how this was legitimized by democratic governments are examined. To access the version of
Recebido: 06.07.20 Aprovado: 08.10 .20

I. Luis Orellana Urtubia es doctor en estudios americanos, académico e investigador del Instituto de Estudios Internacionales (Inte). Editor académico de la Revista Cultura y Religión de la Universidad Arturo Prat, Tarapacá, Chile. <luis_ubl@yahoo. com>.

\section{Evguenia}

Fediakova es Ph.D en ciencias políticas, investigadora del Instituto de Estudios Avanzados (Idea) de la Universidad de Santiago de Chile. <evguenia. fediakova@usach.cl> 
different actors between 1973-1991 we went to primary sources such as publications in the written, visual, specialized magazines, documents and books.

Keywords: Te Deum. Evangelical. Chile. Pastors. Religion. Politics.

\section{Introducción}

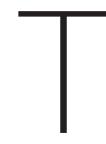

ras el golpe militar del 1973 en Chile, al poco andar los evangélicos irrumpen como un nuevo actor público, cuyo símbolo más significativo de su avidez fue el Servicio de Acción de Gracias, o Te Deum Evangélico. No obstante, para poner en escena el servicio religioso debieron ocurrir dos hechos notables que revelaron el capital religioso de los evangélicos. Primero fue la "Declaración de apoyo al gobierno militar del 13 de diciembre de 1974" manifestación que dio la vuelta el mundo (Puente, 1974; Lagos, 1988; Stoll, 1991; Bastian, 1994; Lowy, 1999; Mansilla \& Orellana, 2018). Luego vino la organizado el Consejo de Pastores integrado por los mismos pastores que hicieron la declaración de apoyo a la dictadura militar y un sector numéricamente mayoritario de los evangélicos en Chile logran realizar el primer Te Deum Evangélico en el templo de pertenecía de la Iglesia Metodista Pentecostal de Chile, donde asistió el presidente de facto Augusto Pinochet y las máximas autoridades del país. Esta ceremonia, no solo se mantuvo durante la dictadura militar (1973-1989), también continuó en los gobiernos democráticos (19902020) no exentos de polémicas y disputa por organización y realización. El Te Deum Evangélico no solamente significó la formación de una nueva fuente de legitimación para el gobierno militar, sino que también simbolizó la irrupción en la esfera pública chilena de un actor religioso, hasta ahora desconocido, que presentó con fuerza sus demandas de nuevo estatus jurídico, posiciones políticas y reconocimiento social. Por primera vez en la historia de Chile el rol monopólico que tenía la Iglesia católica en el campo religioso nacional ha sido desafiado por otro actor confesional que exigía la igualdad simbólica, social y cultural.

Desde sus inicios, este acto junto con tensionar las relaciones entre los organizadores de Te Deum y las iglesias protestantes que reafirmaban su independencia de los gobiernos y más aun de un régimen que había alcanzado el poder mediante un sangriento golpe de estado. También, desató una polémica con un sector importante de la Iglesia Católica en 1975. Es decir, desde lo simbólico, el campo religioso protestante chileno se ha visto perturbado no solo en 1975 , lo ha sido en forma casi permanente; tanto por disputas en su organización, discursos, legitimidad o pugnas por el lugar de su realización como lo fue en el año 2000 cuando sus organizadores decidieron por pugnas con el obispo Vásquez su traslado a la ciudad de Curicó: "El presidente chileno Ricardo Lagos mantuvo una tradición iniciada a mediados de 
la década del 70 y asistió al culto celebrado por la iglesia evangélica el 10 de septiembre en Acción de Gracias por la Patria y conocido como Te Deum Evangélico" (Capitulo 30, 2000: 10-11). Pese a estas tensiones, ningún gobierno de turno se ha negado asistir, independientemente de las polémicas suscitadas por haberse gestados en dictadura y desde lo sagrado dar legitimidad al gobierno militar en momentos que se violaban los derechos fundamentales de las personas, antecedente eludido por los gobernantes. A pesar de que las nuevas sociedades "tácitamente no instituyesen nuevas y profundas referencias y alusiones a lo mítico-religiosas para proceder a su legitimación", no obstante, la historia demuestra que todo proceso de "legitimación implica siempre una forma u otra de contacto con lo sagrado" (Duch, 2014: 64) de ahí que su realización ha causado permanentes reyertas. Pues al parecer, "otra vez trono y el altar" se nos presentan juntos, como afirmo el profesor Eugenio Araya (1989: 79-82) rector de la Comunidad Teológica Evangélica de Chile al formular duras críticas al explicito apoyo a Pinochet por obispos y pastores en el Te Deum Evangélico a solo 18 días del referéndum del 5 de octubre de 1988 cuando la dictadura fue derrotada en las urnas. En nuestro caso, el Te Deum tanto Evangélico y ecuménico habidos en dictadura, han continuado en los gobiernos democráticos y laicos dando cuenta que la perdida de control o desregulación de lo sagrado por parte de las grandes religiones institucionalizadas y heredadas se situaban en la sociedad chilena (Hervieu-Léger, 2004). Por consiguiente, nuestro análisis buscara responder la interrogante ¿por qué el Te Deum Evangélico gestado por un sector religiosos minoritario en los inicios de un gobierno dictatorial ha trascendido a los gobiernos democráticos? ¿qué factores socio culturales y políticos han sido determinantes en su consolidación?

Consideramos, pendiente un estudio científico multidisciplinario que nos permita conocer en forma integral el origen, desarrollo y evolución de este servicio religioso que ha pasado a ser tradicional para los evangélicos. Nos parece relevante analizar las causas, el contexto y las consecuencias de la salida al espacio público de las iglesias evangélicas tras el golpe militar del 1973 con la realización de su Te Deum.

Chile es el único país de América Latina, donde el Te Deum Evangélico se realiza con la misma solemnidad, participación de máximos líderes de la República y amplia cobertura mediática que el Te Deum Ecuménico. Pese a su importancia simbólica y cultural uno de los hechos más significativos del acercamiento entre este actor religioso minoritario y el poder político en 1974, ha sido escasamente estudiado desde las ciencias sociales y religiosas en Chile y en América Latina. Jean Pierre Bastián (1997) lo menciona como un notorio logro de la minoría religiosa chilena. Humberto Lagos, uno de los sociólogos que tempranamente trabajó el tema argumenta que este servicio 
cumplirá la función legitimación supletoria y necesario al gobierno militar por la ausencia del legitimador principal católico, y que aquella función se transformará en medio de represión "oficial" contra la institución religiosa mayoritaria y en contra de las iglesias evangélicas criticas del poder militar (Lagos, 1988: 190).

Las investigadoras Catoggio y Ortega (2011) se refieren al Te Deum como un ejemplo de intercambio de los bienes simbólicas. La dictadura militar chilena ha tenido varias fuentes de legitimación: la Guerra Santa contra marxismo, el "milagro" de reformas neoliberales, su "rol mesiánico" de salvar a la civilización cristiana occidental. Una de las más importantes fuentes de la legitimación del gobierno cívico militar ha sido el apoyo que le brindó un considerable sector de evangélicos y pentecostales. Otros abordajes, han sido más bien breves y tangenciales con un carácter ensayístico realizado en ocasiones especiales y emitidos en revistas y periódicos de circulación interna del mundo evangélico. Las opiniones y reflexiones "posteriores" más significativas son los publicados en 1990 y 1991 en Evangelio y Sociedad, revista editada por el Servicio Evangélico para el Desarrollo Sepade (Sepúlveda, 1990: 2; Equipo Evangelio y Sociedad, 1991: 24-27). De igual manera las reflexiones de Manfred Svensson (2012: 12) publicadas en prensa evangélica.

El objetivo de este artículo es demostrar, mediante un examen socio histórico cómo los Te Deum evangélicos se convirtieron en el símbolo de la salida de cristianos no católicos a la participación política y sirvieron como canal de legitimación y elevación de estatus de una minoría religiosa que reclamaba respeto y reconocimiento público, pero sin considerar el precio ético que eso conllevaba y cómo este ha trascendido durante el periodo democrático.

Desde lo metodológico, nuestro, abordaje será a partir del nuevo rol de los evangélicos a nivel público nacional analizado desde dos perspectivas teóricas: la desprivatización de las religiones en el mundo moderno de José Casanova (1994), y la teoría de campo religioso de Pierre Bourdieu (2006).

En una reconsideración radical de la relación entre la religión y la modernidad, José Casanova (1993) evalúa las funciones que las religiones pueden desempeñar en la esfera pública de las sociedades modernas. El sostiene que durante la década del 80 ', las tradiciones religiosas de todo el mundo, desde el islamismo político a la teología de la liberación católica, comenzaron a hacer su camino fuera de la esfera privada e inserta en la vida pública, causando la "desprivatización" de la religión. Por tanto, las instituciones religiosas dejan de ser meras instituciones de administración de la atención pastoral a las almas individuales, acentuando su rol como fuerzas políticas y sociales, planteando preguntas acerca de las reivindicaciones de 
entidades como las naciones y los mercados, dejan de ser "valor neutro", y agotando las tradicionales conexiones de empresas privadas y públicas de la moralidad. Por otro lado, tanto en Chile y América Latina el "campo religioso" monopolizado por el catolicismo, desde los años 70 empezaba a ceder ante la aparición de nuevos agentes; campo definido por Bourdieu (2006) como el espacio en el que el conjunto de actores e instituciones religiosas producen, reproducen y compiten en la distribución de bienes simbólicos de salvación.

En el caso de Chile, los evangélicos, esta minoría religiosa invisibilizada por más de medio siglo, irrumpe en el ámbito político en 1974-1975. Primero, lo hace con una declaración pública de apoyo a la dictadura, luego, con la inauguración de una catedral y una ceremonia religiosa llamada el Te Deum Evangélico. Con el tiempo, este culto llegó a ser parte de las tradiciones religiosas habituales, marcando cambios que han pasado en la sociedad y política del país: los evangélicos y pentecostales, de un sector silenciado, marginalizado e ignorado, se convirtieron en un actor público reconocido que demostró su capacidad para presentar sus demandas a igualdad de derechos, de estatus jurídico y el mismo respeto de los cuales disponía la Iglesia Católica, rompiendo su monopolio en el campo religioso nacional (Canales, 2000; Puente, 1975; Lagos 1988; Bazley, 1995). Por consiguiente, la reestructuración del campo religioso será nuestro segundo referente teórico pues las acciones de los evangélicos y pentecostales como nuevos actores vino a favorecer, diversificar, individualizar y pluralizar los "productores de bienes simbólicos de salvación", debido al fortalecimiento de garantías para la libertad religiosa por parte del estado, el aumento de la multiplicidad de creencias y actores políticos que buscan alianzas con los nuevos agentes de lo sagrado como fue el caso chileno (Bourdieu, 2006; Dianteill \& Lowy, 2009; Hervieu-Léger, 2004).

La estructura del trabajo será organizada de la siguiente manera: en la primera parte, nos referimos a la evolución histórico-social de los evangélicos en Chile como una minoría "invisible", desde el principio del siglo XX hasta el golpe militar; en la segunda, demostraremos cómo el acercamiento entre los evangélicos y el gobierno de Pinochet a través de los Te Deum permitió a la minoría religiosa posicionarse como actor público reconocido; en la tercera parte, analizaremos las relaciones entre los organizadores de los Te Deum y los gobiernos democráticos; finalmente, en la cuarta analizaremos polémicas y debates sobre la continuidad de la ceremonia tras el fin del gobierno militar. Para alcanzar nuestro objetivo hemos recurrido como fuentes primarias las publicaciones de la prensa escrita, visual, revista especializadas, documentos y libros que nos permita acceder a la versión de distintos actores y del cómo y por qué se produjo el acercamiento de este sector religioso con el poder político autoritario entre 1973-1989 y su y sus convergencias con los gobiernos democráticos. 


\section{Los evangélicos y la sociedad chilena}

1. Los datos censales indican claramente que durante la primera década de crecimiento Pentecostal se logró casi un 1.5 por ciento de la población mayor de 15 años, porcentaje que se mantuvo en la segunda década (1920-1930). Cabe destacar que se trató de una década con fuertes restricciones a la libertad de conciencia, de expresión políticosocial y de expresión religiosa, ya que es solo a partir de la Constitución de 1925 que el Estado de la República de Chile pasó a ser laico. Anteriormente la confesión católica era oficial. Durante la década 19301940 los evangélicos aumentaron su porcentaje en $61 \%$, luego de 1940 a 1952 aumentaron su porcentaje en $74 \%$, en periodo de 1952 a 1960 aumentaron su porcentaje en $37 \%$, para luego aumentar en porcentaje en $11 \%$ en la década de 1960 (Corvalán, 2009: 74).
La presencia de los evangélicos y protestantes en la vida y desarrollo de la sociedad chilena es ampliamente estudiada y conocida: su rol republicano en la guerra por la independencia, colonización del sur del país, su aporte al desarrollo de la educación (fundación de colegio presbiteriano, colegios metodistas en Santiago e Iquique) (Ortiz, 2009; Kessler, 2019). Pero hubo un hecho que marcó fundamentalmente la historia de los evangélicos en Chile y su importancia para la historia y sociedad: la irrupción de un despertar religioso inusual en la Iglesia Metodista de Valparaíso en 1909. Este hecho dio inicio a la movimiento pentecostal chileno que hoy constituye la principal minoría religiosa en Chile, y representa el 70\% de la población evangélica (Hoover, 1948; Vergara, 1962; Kessler 2019; Lalive d’Epinay, 1968; Sepúlveda, 1999; Orellana, 2008; Mansilla, 2009, Corvalán, 2011).

El pentecostalismo, nacido en los sectores más pobres y discriminados de la sociedad, se perfiló como un fenómeno aislacionista, que, siendo rechazado por la sociedad chilena, este a su vez la refutaba, desde la política hasta la educación, consideradas como esferas que "contaminaban" a un verdadero cristiano. (Palma, 1988; Galilea, 1988; 1990; 1991; Cleary \& Sepúlveda, 1998; Mansilla, 2005). Para los pentecostales, no había sentido alguno en participar en la política ni enviar a los hijos a estudiar, pues la inminente Segunda Venida de Cristo les borraba toda la necesidad de participar en cosas tan "mundanas" y transitorias como la militancia en partidos políticos o la educación universitaria (Tennekes,1985; Mansilla 2009; 2016).

Durante más de 60 años el pentecostalismo permaneció dentro de la sociedad chilena como un actor silencioso, invisible, maltratado y opacado por el casi omnipresente catolicismo y la competencia ideológica entre al marxismo y el anticomunismo de la época de la Guerra Fría. La izquierda los tildaba como pro norteamericanos (Vistazo, 1963; Labarca, 1969) y la derecha como anti católicos o cercanos al protestantismo extranjero (Hurtado, 1941; Mansilla \& Orellana, 2018). En la época de las contiendas ideológicas, nadie prestaba atención a un actor religioso minoritario, reducido a la vida privada, que aparentemente no cabía en las principales narrativas políticas de este período, pues se refugiaba en sus comunidades (Piñera, 1961; Lalive d'Epinay, 1968; Willems, 1967; Tennekes,1985).

No obstante, las iglesias evangélicas y pentecostales crecían fuertemente ${ }^{1}$, pero ni el mundo político ni el académico tenían capacidad ni el tiempo para percibir que el campo religioso chileno ha cambiado profundamente, dando lugar a la formación de un nuevo actor político y social que tendría relevancia en la vida política del país 
durante los próximos 30 años. El sector pentecostal aún no presentaba ambiciones político-sociales ni intentos de competir con la Iglesia Católica o actividades político-partidistas, pero comenzaba a darse cuenta de su creciente peso demográfico, cultural y del capital religioso que constituía (Fediakova, 2013; Mansilla, Orellana \& Panotto, 2019).

\section{Te Deum Evangélico, dictadura militar e impacto}

El golpe militar del 11 de septiembre del 1973 y el término de la democracia no solo acabaron con la "vía pacífica al socialismo" y determinaron la victoria de Estados Unidos en esta "batalla" de la Guerra Fría, sino también dividieron la vida de los chilenos en dos, sus familias, instituciones, partidos, iglesias. Pese que la Iglesia Católica no pudo estar de acuerdo con el proyecto socialista de la Unidad Popular, tampoco apoyó las prácticas violentistas del régimen militar de persecuciones, desapariciones y violaciones a los derechos humanos. Por lo consiguiente, la Iglesia Católica de Chile quitó su apoyo y legitimidad al gobierno de Augusto Pinochet, y el régimen se vio obligado a buscar otras fuerzas de legitimación religiosa de su actuar político y social tanto al interior mismo de la Iglesia Católica como fuera de ella ${ }^{2}$. Este fue el momento en que las iglesias evangélicas y pentecostales acuden a su capital de legitimador religioso y simbólico (Díaz, 2014; Lagos, 2001).

Es poco probable, que el general Augusto Pinochet supiera a cabalidad la historia del pueblo evangélico de Chile, su evolución demográfica e importancia social. Nacido en la familia católica, al igual que para la mayoría de los chilenos, el recién declarado Presidente del país tenía escasos conocimientos sobre los conceptos teológicos de esta minoría religiosa, su situación socioeconómica y sus anhelos de competir con la Iglesia Católica. Pero sí, los artífices del golpe militar del 1973 y muchos pastores evangélicos tenían algo importante en común: su profundo anticomunismo. En plena época de la Guerra Fría la división del mundo en amigos y enemigos era absolutamente clara: para la mayoría de los militares chilenos, era el comunismo soviético la amenaza principal para la libertad y prosperidad del mundo occidental. Y para los evangélicos, lo era por su ateísmo declarado, siendo la sociedad que rechazaba a Dios.

Las ceremonias religiosas católicas que tenían lugar en la Catedral de Santiago en el mes de septiembre, datan de la época de la Independencia Nacional. El año 1970 se convirtieron en ecuménicas, por iniciativa del recién electo Presidente Salvador Allende. El líder del gobierno de la Unidad Popular sugirió al cardenal Raúl Silva Henríquez, entonces Arzobispo de Santiago, que era conveniente que este acto
2. Como lo fue

el obispo de

Valparaíso Emilio

Ruiz Covarrubias, el obispo castrense, e nuncio apostólico, o el padre Raúl Hasbún. Pérez de Arce, Hermógenes. Historia de la revolución militar chilena 1973-1990 Santiago: Editorial El Roble, 2018. Sánchez, Marcial y Rodrigo Moreno. Historia de la Iglesia en Chile. Tomo V: “Conflictos y esperanza, remando mar adentro"

Santiago: Editorial Universitaria, 2017. 
3. Noticiero 60 minutos. TVN, 14 Set. 1975.

4. Sobre este hecho singular en la historia de las Iglesia evangélicas chilena la fuente primaria que disponemos es un pequeño libro de Pedro Puentes Oliva. Posición Evangélica, Un documento que define posiciones. Santiago, Editora Nacional Gabriela Mistral, s/d. litúrgico reflejara la diversidad y pluralidad religiosa presente en nuestro país. El primer Te Deum Ecuménico, que incorporó a diversas iglesias evangélicas, a las iglesias ortodoxas presentes en Chile y a la Comunidad Judía, se celebró con ocasión de la trasmisión del mando entre los Presidentes Frei y Allende. Desde entonces, cada 18 de septiembre se celebró en la Catedral de la Iglesia Católica de Santiago, exceptuándose el año 1973, cuando, dadas las circunstancias que vivía el país, el Cardenal Silva Henríquez resolvió reemplazarlo por una "Oración por Chile".

Un año después, los evangélicos y pentecostales anunciaban su importancia en la esfera pública nacional con la inauguración de la Catedral Evangélica el 15 de diciembre de 1974 y luego con el primer Servicio de Acción de Gracias o Te Deum Evangélico, celebrado el 14 de septiembre de 1975, en el templo central de la Iglesia Metodista Pentecostal, tradicionalmente conocido como Jotabeche, y desde entonces como la "Catedral Evangélica" ${ }^{3}$. Como pasos previos al inicio de esta práctica el 13 de diciembre de 1974 tuvo lugar, en el edificio Diego Portales (que en ese momento era la sede del Gobierno) un acto de apoyo al Gobierno Militar convocado por los actores religiosos de las principales iglesias evangélicas y pentecostales del país. Allí, se leyó una declaración de apoyo al Gobierno y agradecimiento por haber salvado a la nación del comunismo, firmada por 32 obispos y pastores que representaban a la iglesia evangélica chilena ${ }^{4}$ (Mansilla \& Orellana 2018). Esta jornada y la declaración fue un requisito solícito para que el presidente de facto aceptara ir a la inauguración de la Catedral Evangélica. Hecho inédito, que ningún jefe de Estado si quiera pensó visitar un templo evangélico en toda la historia del país.

Desde esta fecha, los Te Deum evangélicos se convierten en el símbolo de colaboración entre el poder político que estaba en busca de legitimación, y las iglesias evangélicas, en demanda de reconocimiento e igualdad de derechos con la Iglesia Católica. Por primera vez, un presidente de la República asistía al Servicio de Acción de Gracias Evangélico en la Catedral Evangélica principal icono de fe reformada, pero de origen pentecostal local. Por primera vez en 400 años el monopolio de la Iglesia Católica y su dominio del campo religioso estaba siendo desafiado por un actor religioso emergente y de rostro marginal.

Las palabras del pastor Francisco Anabalón de la Iglesia Pentecostal Evangélica durante la homilía en el culto correspondían plenamente al clima divisorio, ideologizado y polarizado que caracterizaba tanto a la sociedad chilena como al mundo entero: "Rechazamos doctrinas e ideologías totalitarias que pretenden imponer el odio y la violencia como el motor de la historia de los pueblos, pero con la misma vehemencia también rechazamos la venganza como medio de corrección" ( $L a$ 
Tercera, 15 Set. 1975). Al mismo tiempo, este discurso dio parámetros y pautas a seguir para la mayor parte de los Te Deum evangélicos posteriores.

La realización del Te Deum "alternativo" al Ecuménico, generó polémicas. La Iglesia Católica interpretó como una maniobra de las autoridades militares "castigándola" por sus críticas por las violaciones los derechos humanos. Algo como un castigo simbólico, en este contexto fueron muy difundidas las declaraciones del Obispo Carlos Camus referidas a esta práctica. El Obispo Camus, perteneciente al sector ecuménico del catolicismo, evaluó al Te Deum Evangélico como competencia y al mismo tiempo como un gran error "táctico, estratégico, pastoral" que alejaba a los evangélicos de pequeñas comunidades y capillas, optando no por el servicio a la gente, sino por organizar ostentosos rituales con la presencia de máximas autoridades del país. Como se puede deducir, que gran reproche del Obispo consistía en que los pastores se alejaron de sus valores espirituales, privilegiando los "valores terrenales" como "tener una gran Catedral y reconocimiento oficial" (Vea, 16 Out. 1975: 10). Se puede apreciar la desconfianza de actores católicos a sus contrincantes del mundo protestante, cuando el obispo se refiere a las iglesias evangélicas como a las "sectas" que tienen un "complejo de inferioridad" y lo buscan paliar con la construcción de grandes catedrales.

En la carta de respuesta a las declaraciones del Obispo Camus que redactan los pastores evangélicos, se deja claro que en el campo religioso los católicos ya no son únicos que pretenden liderar los vínculos políticos y determinar valores éticos de los chilenos: "Este gobierno... tenemos que decirlo, es el primero que da a la iglesia evangélica la debida consideración a sus valores espirituales que como fuerza viva aporta a nuestra sociedad. Esto, desgraciadamente, molesta al representante de la Iglesia Católica y nos prueba que su bullado ecumenismo no es una actitud sincera". (Zelada, 1975: 14-15): Consideramos que estos descontentos y molestias, simbolizan el hecho de que la sociedad y la Iglesia Católica de Chile por primera vez se dieron cuenta que el campo religioso nacional de su dominio ha ingresado un nuevo actor para dar paso a uno mas diverso (Parker, 1997). Esta irrupción evangélica como agente de lo sagrado será "un fermento de reestructuración del campo religioso y de la estructura social" (Dianteill \& Lowy, 2009: 184).

El propio Gobierno Militar no tuvo empacho en presentarlo como una conmemoración del 11 de septiembre de 1973. Las iglesias evangélicas no participantes en él, especial aquellas que se agrupaban en la Asociación de Iglesias Evangélicas de Chile (AIECH), desautorizaron la representatividad y reivindicaron la tradicional independencia política de los evangélicos (Equipo Evangelio y Sociedad, 1991: 24). 
Los propios organizadores, agrupados en el Consejo de Pastores, mantuvieron por años en la ambigüedad el sentido del acto, diciendo oficialmente que se trataba de un Servicio de Acción de Gracias por la independencia de Chile, pero dando en la práctica igual importancia a la referencia a los hechos del 11 de septiembre. Durante los años 80s, el Te Deum Evangélico fue adquiriendo paulatinamente un perfil definido como acto protocolar evangélico, en el marco de las fiestas patrias, y sus oradores procuraron mostrar una independencia más nítida, dando lugar a la preocupación por la violencia y ciertos problemas sociales.

Este Te Deum, se convirtió en otra manifestación de cuan divididos quedaron todos los sectores de la sociedad tras el golpe militar y puso comienzo a la formación del mito generalmente compartido por los chilenos, que todos los evangélicos y pentecostales eran conservadores, autoritarios y partidarios de la dictadura militar (Löwy, 1999: 145; Bastian, 1990: 226; Pérez, 2017: 152).

Refiriéndose al rol de la religión en los procesos de legitimidad de un gobierno autoritario, Humberto Lagos (1988: 140) sostiene en su libro Crisis de la esperanza lo siguiente: "La importancia cultural del hecho religioso en la sociedad chilena, atribuye a las iglesias una función fundamental en la construcción de consensos necesarios para la permanencia del dominador autoritario". Desde muy temprano la Iglesia Católica tomó distancia del Gobierno Militar autoritario. Enfrentado al conflicto, el gobierno necesitaba resolver esto positivamente. En consecuencia, las vías principales fueron utilizar los grupos religiosos minoritarias proclives al modelo político autoritario y la radicalización del discurso militar reclamando su intervención como destinada a servir a la fe cristiana contra un enemigo ateo. Inserto en este plan estratégico de buscar legitimad religiosa surgen los Te Deum evangélicos, pues según Bourdieu (2009: 84): "la iglesia, se encuentra investidas de una función de mantenimiento del orden simbólico... contribuye, por añadidura, al mantenimiento del orden político". Resulta comprensible que Te Deum desde sus inicios en septiembre de 1975, se haya transmitido en vivo y directo a todo el país por Televisión Nacional de Chile con la más amplia cobertura noticiosa. Todos los canales hasta hoy lo tienen en sus titulares, por tanto, es una noticia que circula en el país y llevado al mundo por las agencias de noticias. Los medios escritos también cubren el hecho, lo que ha facilitado su estudio y acceso a fuentes primarias. Las portadas de la prensa evangélica se cubren de fotos y titulares donde las imágenes del Jefe de Estado junto a pastores y obispo, es un hecho ya tradicional. Esto a su vez representa la cercanía de los líderes religiosos con los políticos en el poder, primero fue con general Pinochet y luego con Aylwin, Frei, Lagos, Bachelet y Piñera. Asimismo, la atención mediática al Te Deum, la presencia de las autoridades y la arquitectura gigantesca de la Catedral creaban la sensación que el evangélico chileno es idénti- 
co, monolítico y uniforme, sin tener distintas corrientes, diversas teologías y actitudes hacia el poder y autoritarismo disímiles.

Además, los pastores en provincias y regiones no tardaron en imitar los esquemas de relacionamiento del Consejo de Pastores con la autoridad militar tanto en su forma de organización, vínculos y actos de apoyo al Gobierno Militar a nivel local. Hoy, es común ver como la prensa local en el mes de las fiestas nacionales (septiembre) informa de esta ceremonia que ya es parte del acervo cultural chileno. Por su parte, al interior de las asambleas, convenciones y conferencias regulares de las iglesias, especialmente pentecostales, se introdujo un nuevo actor: "los representantes del Gobierno Militar" quienes se hicieron invitar y muy luego introducir la práctica de contar con la presencia de la autoridad de gobierno a sus reuniones especialmente aquellas masivas y públicas. En principio estos fueron recibidos con agrado y simpatía por los líderes evangélicos como ocurrió en la Iglesia Metodista Pentecostal de Chile en su Conferencia Anual de 1975 que fue titulado en la revista de la Iglesia en los siguientes términos: "Obispo Mancilla saluda al Intendente, Coronel Ramírez en la Conferencia de Angol" 5 . Los pastores largamente ignorados, por primera vez se sintieron valorados por la autoridad, un hecho inédito en la historia de los evangélicos. Desatando a sí, un proceso de reciproco reconocimiento y legitimidad entre un actor político y un religioso y que perdura hasta hoy.

Uno de los elementos más seductores para el mundo político tanto en el Gobierno como oposición o aquellos que buscan legitimidad social es contar con el apoyo en los sectores religiosos; más aún, si se trata de un movimiento en expansión en los últimos 50 años como lo ha sido la iglesia evangélica chilena. Por tanto, uno de los protagonistas silenciosos más significantes en el desarrollo de los Te Deum evangélicos ha sido el templo catedral de la Iglesia Metodista Pentecostal de Chile conocido como "Catedral Evangélica", o Iglesia de Jotabeche. Este templo, es probablemente el santuario más conocido y representativo en el imaginario colectivo del mundo evangélico del país. Ya sea, por el papel de trascendencia social y política jugado, por la valoración simbólica otorgada por pastores y congregaciones, por el significativo emplazamiento en el espacio urbano o por sus características arquitectónicas que reafirma su pretendida primacía evangélica nacional y la búsqueda de proyección de su arraigo histórico (Vidal, 2012: 198-204).

Sin nos referimos al Servicio de Acción de Gracias como un acto religioso, es importante recalcar que, pese a que tiene lugar en el Templo de la Iglesia Metodista Pentecostal, la ceremonia misma tiene pocas características pentecostales: lejos de la emocionalidad, espiritualidad y espontaneidad de reuniones evangélicas carismáticas, el Te Deum aparece como un culto sumamente ceremonioso, calculado,
5. Conferencia

Anual de la Iglesia Metodista Pentecostal de Chile Argentina y Perú. Chile Pentecostal, $\mathrm{n}$. 606, p. 5, Temuco, Abr./Jun. 1975. 
6. El Obispo Javier Vásquez falleció el 25 julio de 2003 , fue pastor entre 1965-1985 y obispo vitalicio de la Iglesia Metodista Pentecostal (19852003) (La Voz Pentecostal, n. 45, p. 12-13 2009). Lo reemplazo en su cargo de pastor de la Catedral Evangélica su ex secretario, el laico Eduardo Durán Castro quien el 20 de abril de 2019 en medio de escándalos morales y financieros fue públicamente expulsado por la congregación de la Catedral Evangélica (Mansilla y Orellana, 2019).

7. De acuerdo a La Constitución del 1980, " Disposición Decimocuarta Transitoria disponía la continuidad de Pinochet como Presidente de la República por 8 años, al cabo de los cuales, y de acuerdo a las Disposiciones Vigesimoséptima a Vigesimonovena Transitorias, los Comandantes en Jefes de las Fuerzas Armadas y el Director General de Carabineros por unanimidad propondrían al país el nombre de una persona que ocuparía el cargo de Presidente de la República por 8 años más, sujeto a ratificación en un plebiscito, designación que recayó en Augusto Pinochet". Disponible en: protocolar, cuyos organizadores están concentradas en las autoridades presentes y no en la comunicación con lo divino.

Los mismos dirigentes que organizaron el acto cívico de apoyo al gobierno militar, del 13 de diciembre de 1974, continuaron las conversaciones con las autoridades políticas para concluir una estrategia que facilitara la permanencia de la relación de apoyo. Primero, en junio del 1975 fue creado el Centro Evangélico Nacional Coordinador de Actividades (CENCA), cuyo logro fundamental fue la formación un mes después del Consejo de Pastores de Chile que lo reemplazo en sus funciones y se convirtió en el principal organismo de coordinación de las relaciones entre las iglesias evangélicas firmantes del documento de apoyo al gobierno militar, y el gobierno de Augusto Pinochet (Lagos, 1988: 184-189). Este organismo tuvo monopolizada la conducción de los Te Deum evangélicos hasta el año 1999 en forma ininterrumpida y siempre bajo el liderazgo de pastores conocidos por su cercanía con Pinochet como lo fueron Pedro Puentes, Ricardo Ramírez, Francisco Anabalón y especialmente el Obispo Javier Vásquez. Este último en su calidad de dueño de casa hasta $2003^{6}$, no solo pretendía hablar en representación de todos los evangélicos a nivel nacional, algo que aprendió de su antecesor, sino que convirtió a la Catedral Evangélica en un espacio habitual para manipulación política de sus feligreses, indicaciones electorales, declaraciones favorables a los partidarios del régimen autoritario primero, y luego con los gobiernos democráticos a favor de bienes corporativos e interés individual (EI Vistazo, 1963; Candía, 1985; Araya, 1989; La Tercera, 1991; Svensson, 2012).

\section{Te Deum y el retorno de la democracia}

Con la puesta en marcha de la Constitución Política de 1980 en marzo de 1981, se abrieron espacio para que los opositores al Gobierno del General Pinochet pudieran expresar su malestar y exigir el término del exilio y una pronta vuelta a la democracia $^{7}$. Así surgieron en 1983 las protestas nacionales que fueron reprimidas violentamente por la dictadura. El país se tornaba violento, varios actores como la Iglesia Católica llamaban a erradicar las confrontaciones. El Te Deum de 1984 los pastores harán lo propio, pero desde su lógica. El sermón lo expuso Álvaro Yáñez, pastor pentecostal de Valparaíso, hijo de uno de los fundadores del pentecostalismo chileno Ramón Yáñez discípulo del pastor W. Hoover ${ }^{8}$. No obstante, el Te Deum demostró la fuerte polarización del sector evangélico y la consolidación de clara conciencia sobre sí mismo como actor público y político nacional. El Pastor Yáñez declaró:

Responsablemente declaramos que, como cristianos, no somos apolíticos, si por tales se entiende a los hombres apáticos, indiferentes, indolentes; a los que niegan la realidad o escapan de ella... 
Hablamos de política con mayúscula... Aunque la reconciliación con el hombre no es lo mismo que la reconciliación con Dios, ni el compromiso social es lo mismo que la evangelización, ni la liberación política es lo mismo que la salvación, afirmamos que la evangelización y la acción social y política son parte de nuestro deber cristiano. No debemos temer denunciar el mal y la injusticia, donde quiera que éstos existan (La Tercera, 17 Set. 1984).

El Te Deum Evangélico de 1988, y a solo 18 días del plebiscito nacional del 5 de octubre, donde la ciudadanía debía decir mediante el voto universal la continuidad del General Pinochet por ocho años más en la presidencia. La imagen colectiva que proyectaron los medios era que el pueblo evangélico de Chile estaba por la continuidad del gobierno de facto al proclamar en forma religiosamente en cubierta su apoyo. El Obispo Vásquez declaraba abiertamente: "Estamos firmes con la libertad y dispuestos a defenderla" (La Tercera, 18 Set. 1988). El sermón estuvo a cargo del Obispo Carlos San Martin de la Iglesia Unida Metodista Pentecostal, en lo medular sostuvo:

Quien siembra odios, tendrá que cosechar odios. No olvidemos que la cosecha será siempre más abundante que la siembra. Imposible es que de nuestros hijos logremos una generación pacífica, si la enseñanza que les están entregando sus padres está fundamentada sobre los principios errados y falsos de intriga, odio y violencia. Seguramente, el resultado será funesto y tendremos hijos más violentistas y con más odio, atrayendo con ello más quebranto a nuestra sociedad (La Tercera, 18 Set. 1988).

Estas prédicas y sermones, a través de lenguaje religioso transmitieron claramente su mensaje político, la lealtad inquebrantable al gobierno militar y disponibilidad de defender su permanencia en el poder. La Catedral Evangélica de la Iglesia Metodista Pentecostal no es un simple lugar de oración, sino que se ha constituido en el espacio público, que, crea y distribuye los "bienes simbólicos de salvación", asimismo, produce y divulga también "bienes simbólicos" terrenales como fue el apoyo abierto al régimen militar y a sus campañas electorales. También, se consolidó la imagen de la iglesia evangélica que parece un actor monolítico, uniforme y que goza el pleno apoyo del gobierno. Y los líderes del Consejo de Pastores, aparentemente, esperaban recibir beneficios jurídicos, simbólicos y materiales a cambio de su lealtad al presidente y sus políticas algo que nunca ocurrió (Lagos, 1988: 206217). Pero si quedo el Te Deum como ceremonia religiosa y tribuna pública para un actor emergente y controversial, aunque este se gestó en dictadura.

La sociedad chilena vivía el punto de inflexión en su historia pues el plebiscito del 5 de octubre del 1988 Chile debería decir Sí o No a la permanencia del presidente
$<$ https://www.ben $\mathrm{cl} /$ historiapolitica/ constituciones/deta le_constitucion? handle $=10221.1$ / 60446>. Consultado el 24 Jun. 2020

8. El pastor Willis C. Hoover, misionero de la Iglesia Metodista de EE.UU. fue el protagonista del "despertar" pentecostal en Valparaíso en 1909 y fundador de la Iglesia Metodista Pentecostal y la Iglesia Evangélica Pentecostal que constituyen la matriz del movimiento pentecostal chileno. 
Pinochet en el poder durante los próximos ocho años. Toda la vida política, social y cultural del país estaba absorbida por el enfrentamiento de las campañas "Por el Sí" o "Por el No". En este Te Deum se hizo claro que los líderes del Consejo de Pastores hicieron su opción: el reportaje de la Televisión Nacional muestra al general Pinochet al entrar a la Catedral rodeado por las pancartas con la palabra "Si". (Televisión Nacional de Chile, reportaje del 12 Set. 1988).

Los sermones y prédicas de pastores que dirigían el culto, tradicionalmente, estaban llenos de adulaciones al presidente del país, agradecimientos a las Fuerzas Armadas por "defender la libertad", a Pinochet en persona -por garantizar la libertad de cultos y "haber erradicado la pobreza". En las declaraciones del obispo Vásquez se notaba claramente que para el Consejo de Pastores y para los militares el marxismo seguía siendo el principal enemigo: "Dios no dijo que Chile será para doctrinas foráneas ni las doctrinas ateas, Chile será para Cristo". El golpe militar seguía siendo interpretado como un hecho mesiánico y profético de salvación, en el cual el obispo se sentía partícipe y precursor a decir en la ceremonia "El 4 de agosto del 1973, cuando un espíritu poderoso me tomó ante muchos testigos que hay aquí y dijo que próximamente habría cambios de estructuras socioeconómicas y políticas, y Chile se libraría de una gran catástrofe. Y así fue. Se cumplió la profecía". Al mismo tiempo, se observa que este sector religioso adquirió la conciencia de sí mismo como "una fuerza considerable", "para defender al país de todos los enemigos", constituyendo "más de 30\% de la población nacional". -Solo, la Iglesia Metodista Pentecostal dirigida por el Obispo Vásquez reportaba 1.500.000 fieles, algo que siempre estuvo en duda (La Voz Pentecostal, 1990: 40, 1995: 5)- cuando en realidad, eran mucho menos. El Censo del 1992 arrojó que el número de evangélicos en el país llegaba al 13\%.

Aparentemente, al igual como Pinochet, el obispo Vásquez y los demás organizadores del Te Deum no tenían duda alguna en el triunfo del Sí en el próximo plebiscito que determinaría la continuidad de la permanencia del general en el poder. Y, siempre dentro de la tradición de esta ceremonia, nunca se abordó el tema de derechos humanos, torturas ni desapariciones. Nunca fueron cuestionadas las reformas económicas de los Chicago boys, niveles de cesantía y pobreza que existían en el país, ni el costo social de las transformaciones neoliberales. Claramente, en su lucha por el reconocimiento y nuevo estatus para de los evangélicos, para el Consejo de Pastores la democracia no presentaba valor alguno.

En el plebiscito del 5 de octubre el General Pinochet fue derrotado, y de inmediato reconocido por los demás integrantes de la Junta Militar. Esto, significó que se debían realizar elecciones libres para presidente, diputados y senadores el año 
siguiente. Comenzaba la transición a la democracia. En este contexto, los obispos y pastores tanto organizadores de los Te Deum y la Catedral Evangélica seguían haciendo campañas para los candidatos de derecha y prestaban abiertamente sus templos para los actos y declaraciones políticas de inclinación e ideológicamente determinada. Indicar, por cual candidato tenían que votar los feligreses para garantizar la continuidad del legado del régimen militar, se convirtió en la práctica habitual del obispo Vásquez (La Voz Pentecostal, entre 1986 y 2003).

El Te Deum Evangélico que se desarrolló el 17 de septiembre de 1989 tuvo una gran afluencia de ministros de estado, candidatos a diputados y senadores. Hernán Büchi, ex ministro de Hacienda del gobierno de Pinochet, lo hizo en su calidad de candidato a la presidencia. La intervención del Obispo Javier Vásquez, fue abiertamente para agradecer al General Pinochet "por ser el único Jefe de Estado en la historia de Chile que ha llegado a nuestro templo, desde 1974 hasta ahora. Lo mismo han hecho intendentes gobernadores y alcaldes en todo el país. Estamos eternamente agradecidos" (La Tercera, 18 Set. 1989). El sermón lo impartió el Obispo Francisco Anabalón quien llamo a la reconciliación en los siguientes términos: "Los evangélicos estamos interesados en el destino de la patria. Tenemos el derecho y aun el deber de demandar de todos cuantos están en el servicio público, que ejerzan, que den ejemplo de conducta en el plano de la convivencia fraterna" (La Tercera, 18 Set. 1989).

Las autoridades democráticas del país parecían estar confundidas frente a este evento religioso tan estrechamente vinculado a la dictadura. El presidente Aylwin en septiembre de 1991 no estaba seguro si seguía asistiendo este culto que se había convertido en el símbolo de reconocimiento mutuo entre el poder militar y los evangélicos. Una vez concluido el servicio el presidente Aylwin declaraba a los periodistas en su despedida: "Como Presidente de todos los chilenos, he creído que debía concurrir cuando un grupo de cristianos oran por la Patria. Sus oraciones me fortalecen, porque un gobernante necesita el apoyo de sus compatriotas y de Dios". Pese a que en un momento declaro que no iba a volver a participar en el Te Deum Evangélico, luego cedió a las voces de sus consejeros políticos que lo convencieron que esta ceremonia ya convertida en una tradición, debía continuar como símbolo de respeto a la libertad y diversidad religiosas. Se afirmaba a sí "la religión en movimiento" (Hervieu-Lélger, 2004). La participación en el Te Deum Evangélico del primer presidente elegido democráticamente desde el 1970 comprobó que los cristianos no católicos ganaron su espacio en la esfera pública y consolidaron su reconocimiento por las autoridades y la sociedad como un significativo actor social y la minoría religiosa más importante, independientemente de su orientación ideológica. Desde ahora en adelante los máximos dirigentes del país tendrían que asistir los dos Te Deum paralelos, el Evangélico y el Ecuménico. El espacio público y 
reconocimiento social ganados por los evangélicos fueron consolidados posteriormente por la aprobación de la Ley de Cultos en 1999, el 31 de octubre declarado feriado nacional como día de las Iglesias evangélicas y protestantes, capellanías en las fuerzas armadas y en la casa de gobierno. Sin embargo, hasta el día de hoy el Te Deum se mantiene como la presencia pública más importante de los evangélicos en la sociedad y política chilenas.

\section{Te Deum Evangélico como espacio político}

Como hemos mencionado anteriormente, tras el golpe del 1973, el mundo evangélico chileno quedó tan dividido como el católico o político secular. Si bien gran cantidad de pastores evangélicos y pentecostales han expresado su apoyo al gobierno militar, otro sector cristiano no católico desde un principio se comprometió con la causa de protección de derechos humanos, ayuda jurídica a las víctimas y acompañamiento a las familias de los detenidos. Eran organizaciones que hasta el día de hoy son poco conocidas por la opinión pública nacional, en las cuales varios actores evangélicos y protestantes se hicieron frente contra la dictadura: Comité por la Paz, Fundación de Ayuda Sociales de las Iglesias Cristinas (Fasic), Servicio Evangélico para el Desarrollo (Sepade), Confraternidad Cristiana de Iglesias (CCI). Esta última en agosto del 1986 presentó la carta al general A. Pinochet, en la cual, a diferencia de la carta del 1974, se condenaba la pobreza, precariedad y desamparo social que se vivía en el país y el uso excesivo de miedo y la violencia, llamando a respetar los derechos humanos. (Mansilla \& Orellana 2018). De este sector surgieron los cuestionamientos en cuanto a la vigencia y continuidad de Te Deum Evangélico.

Fue la Confraternidad Cristiana de Iglesias (CCl) el primer organismo que públicamente manifestó su crítica y rechazo al Te Deum como encarnación de alianza simbólica entre los evangélicos y la dictadura militar. Uno de los líderes de este sector, el director de la ONG Servicio Evangélico de Desarrollo (Sepade), Juan Sepúlveda, expresaba:

\footnotetext{
Las iglesias miembros de la Confraternidad Cristiana de Iglesias se inclinaron, tempranamente, en favor de un retomo a la práctica de un único Te Deum, aunque profundizando su sentido ecuménico... La CCl, en carta dirigida al Presidente de la República, planteó sus reservas y fundamentó su posición a favor de un único Te Deum Ecuménico, y evitar seguir transformando esta práctica en un campo de disputa religiosa que no contribuye a la unidad nacional (Equipo Evangelio y Sociedad, 1991: 24-27).
}

Con el paso del tiempo El Te Deum Evangélico se convirtió en un tipo de evento al que rutinariamente las autoridades se ven obligadas a asistir, a pesar de que 
prevén lo incómoda que será la situación. Para estos no importa qué se diga desde el púlpito, deben mantener un rostro impertérrito. Ya eso basta para quitar toda seriedad a la situación: aunque quien tiene el micrófono diga cosas sumamente serias y dignas de consideración, difícilmente será recibido, pues no estamos ante un oír libre. De parte del político que asiste, lo que está teniendo lugar es un acto de reconocimiento hacia los evangélicos y ese tipo de acto obliga al asentimiento o al silencio, impidiendo la consideración libre, serena y diferenciada. Que los pastores sientan que han hablado, o que el gobierno sienta que los ha escuchado. En opinión del filósofo M. Svensson ambas conclusiones son en realidad erróneas. Este mismo pensador en referencia al futuro del Te Deum Evangélico dice:

\footnotetext{
La existencia de este acto, como tal vez única instancia de la vida evangélica con amplia cobertura periodística, lo convierte en una catarsis que en lugar de estimular es capaz de incluso inhibir la participación pública seria de los evangélicos. Su eliminación, o una creciente indiferencia del mundo político y periodístico respecto de la ceremonia, contribuirían a una más sana integración de los evangélicos en nuestra vida pública (Svensson, 2012: 12).
}

Los sectores liberales y ecuménicos del mundo evangélico chileno rechazan la legitimidad del Te Deum como producto de una alianza oportunista del gobierno militar con un sector religioso que aprovechó la oportunidad para lograr reconocimiento y beneficios en ausencia de otro actor más poderoso, la Iglesia Católica. Este actor, no alcanzó avizorar que se estaba en el inicio o "el fin de las identidades religiosas heredadas" (Hervieu-Lélger, 2004: 63). Los objetivos de líderes evangélicos que presentaron su apoyo al gobierno militar en 1974 claramente tenían carácter coyuntural y corporativo, que buscaba defender intereses sólo de su propio sector, sin pensar en un amplio proyecto nacional. La búsqueda de privilegios institucionales en su momento prevaleció sobre los valores cristianos, y el edificio o Catedral Evangélica en vez de convertirse en un símbolo de integridad espiritual cristiana, comenzó a asociarse con interés egoísta y mundano, con la lucha por valores y bonificaciones terrenales. A pesar de esto, no podemos quitar la importancia al hecho de que la "desprivatización" de los evangélicos tras su expresión pública de apoyo al golpe militar le ayudó como minoría religiosa en su conjunto a recibir el reconocimiento nacional y la legitimidad de sus demandas a tener la igualdad de derechos jurídicos y culturales. A este proceso, Casanova lo llamo "desprivatización" de la religión moderna, en nuestro caso de las iglesias evangélicas que "abandona la esfera privada y entra en la esfera pública para tomar parte en el proceso en curso de debate": la legitimación discursiva y el nuevo trazado de fronteras". Algo, que se dará una década más tarde, cuando las iglesias interpelaran a los gobiernos democráticos por normativas o leyes que colisionan con sus postulados religiosos. Para 
los evangélicos, será el primer examen: "tendrá que aprender a vivir con el pluralismo religioso, dentro y fuera de la Iglesia" (2000: 300). Pues, muchas veces amplios sectores evangélicos y pentecostales se han anclado a "paradigmas premodernos" de pensamiento y acción. Nos queda la interrogante ¿Podrán situarse a la altura de los nuevos tiempos?

\section{A modo de conclusión}

El Te Deum Evangélico nace como un acto político dentro de contexto político específico. Nace como una institución profundamente negacionista: anticatólica, anticomunista, anti ecuménica (Lago, 1988), anti atea, anti democrática y anti liberal. Se construye no en busca de profundización y elevación de valores espirituales, sino como resultado de intentos de algunos pastores evangélicos de aprovechar el vacío ético-normativo dejado por la Iglesia Católica para satisfacer sus intereses personales, corporativos, políticos y totalmente mundanos. El lenguaje religioso de los organizadores de Te Deum estaba elaborado para expresar estos objetivos. La presencia del presidente de la República en la celebración evangélica más importante tenía muchos significados: la salida del mundo evangélico a la esfera pública, su anhelado reconocimiento por las autoridades y el mundo político, "venganza" al catolicismo y posibilidad de obtener varios símbolos de presencia pública: tener capellanías en el palacio presidencial y en las fuerzas armadas, obtener terrenos para la construcción de templos, visitar cárceles y hospitales. Estos reconocimiento y visibilidad finalmente logrados para el sector fundamentalista y conservador eran para éste mucho más importante que la democracia, defensa de derechos humanos y el costo humano que pagó la sociedad chilena por las reformas neoliberales. Es decir, estas iglesias despreciaron los valores humanos y democráticos para elevar su estatus y codearse con las máximas autoridades del gobierno. Estos oportunismo e instrumentalización de "los bienes de salvación" no les ayudaron a los conservadores a mejorar su imagen en la opinión pública nacional tras el regreso de la democracia. Sin embargo, la consolidación y continuidad del Te Deum Evangélico reflejó la diversificación del campo religioso chileno y significó un importante paso hacia su pluralización (Frigerio y Wynarczyk, 2008).

Continuando con el pensamiento de Svensson, tal vez sea tiempo, de repensar de un modo más profundo no sólo la existencia del Te Deum, sino toda la relación de la vida pública chilena con la religión. Tal replanteamiento no tendría por qué significar una mayor separación de la vida pública y la fe, podría implicar incluso su mayor interacción. Porque una cosa es la separación entre el Estado y las iglesias (separación por la que hay que velar), y una muy distinta es la relación entre la religión y la vida pública, el modo en que la religión motiva y nutre la participación 
política de algunos ciudadanos. Distinguir esas dos cosas sin duda es más viable cuando los actores principales son laicos y no pastores. Pero también si los actores son laicos un sano desarrollo de esta relación entre religión y vida pública debiera dar lugar a la expresión de convicciones robustas sin que nadie se escandalice como ha ocurridos en los últimos servicios.

\section{Referencias}

ARAYA, Eugenio. Los evangélicos, la política y el mundo. Santiago: Comunidad Teológica Evangélica de Chile, 1989.

BASTIAN, Jean-Pierre. La recomposición religiosa de América en la modernidad tardía. In: La modernidad religiosa: Europa latina y América Latina en perspectiva comparada, p. 155-174. México: FCE, 2004.

La mutación religiosa en América Latina. Para una sociología del cambio social en la modernidad periférica. México: FCE, 1997.

Protestantismo y modernidad latinoamericana. Historia de la unas minorías religiosas activas en América Latina. México: FCE, 1994.

Historia del protestantismo en América Latina. México: Cupsa, 1990.

BAZLEY, Bárbara. Somos anglicanos. Santiago: Imprenta Editorial Interamericana, 1995.

BOURDIEU, Pierre. La eficacia simbólica: religión y política. Buenos Aires: Editorial Biblos, 2009.

. Génesis y estructura del campo religioso. Relaciones, v. 27, p. 29-83, Otoño 2006

CANALES, Hermes. Firmes y adelante: evangélicos por la igualdad. Santiago: Auto-edición, 2000.

CANDÍA, Luis Domingo. Nuestro credo es el evangelio, no la política. Diario: Las Ultimas Noticias , p. 18-19. 4 Ago. 1985.

CASANOVA, José. Religiones públicas en el mundo moderno. Madrid: PPC, 2000.

Dimensiones publicas de las religiones en las modernas sociedades occidentales. Iglesia Viva, n. 178-179, p. 395-410, Jul./Oct. 1995. 
. The public religion in the modern world, Chicago: University of Chicago Press, 1994.

CATOGGIO M. S.; ORTEGA., M. Religious beliefs and actors in the legitimation of military dictatoships in the southern corn, 1964-1982. Latin American Perspectives, v. 38, n. 6, p. 25-37, 2011.

CLEARY, E.; SEPULVEDA, Juan. Chilean pentecostalism: a coming of age. In: CLEARY E.; STEWART-GAMBINO, H. Power, politics and pentecostals in Latin America, p. 97-122. Boudler: Westview Press, 1998.

CORVALÁN, Oscar. Distribución, crecimiento y discriminación de los evangélicos pentecostales. Revista Cultura y Religión, v. 3, n. 2, p. 70-91, 2009.

CRISTI M.; L. Dawson. Civil Religions in comparative perspective: Chile under Pinochet (1973-1989). Social Compass, v. 43, n. 3, p. 329-338, 1996.

DEPTO. DE RR.PP. 86a . Conferencia Anual Internacional de la Iglesia Metodista Pentecostal de Chile. La Voz Pentecostal, n. 26, p. 5-7, 1995.

DIANTEILL, Erwan; LOWY, Michael. Sociologías y religiones. Aproximaciones disidentes. Buenos Aires: Manantial, 2009.

DIAZ, Rodrigo. Los lugares de lo político, los desplazamientos del símbolo: poder y simbolismo en la obra de Víctor W. Turner. Barcelona: Gedisa, 2014.

DUCH, Lluís. Religión y política. Barcelona: Fragmenta Editorial, 2014.

DURÁN, Castro. Conferencia Anual Internacional de los 80 años. La Voz Pentecostal, n. 40, p. 40, Dic. 1990.

EQUIPO EVANGELIO Y SOCIEDAD. Los Te Deum, centro de la polémica. Evangelio y Sociedad, n. 11, p. 24-27, 1991.

FEDIAKOVA, Evguenia. Evangélicos, política y sociedad en Chile. Dejando el refugio de las masas, 1990-2010. Santiago: CEEP Ediciones; Idea, 2013.

FRIGERIO, Alejandro; WYNARCZYK Hilario. Diversidad no es lo mismo que el pluralismo. Cambios en el campo religioso argentino (1985-2000) y la lucha de los evangélicos por sus derechos religiosos. Sociedade e Estado, v. 23, n. 2, p. 227-260, 2008 .

GALILEA, Carmen. El predicador pentecostal. Santiago: Centro Bellarmino-Cisoc, 1991. 
El pentecostal: testimonio y experiencia de Dios. Santiago: Centro Bellarmino-Cisoc, 1990.

- Sectas modernas y el contexto socio religioso en Chile. Santiago: Centro Bellarmino-Cisoc, 1988.

HERVIEU-LÉGER, Danièle. El peregrino y el convertido. La religión en movimiento. México: Ediciones del Helénico, 2004.

HOOVER, W. C. Historia del avivamiento pentecostal en Chile. Valparaíso, CL: Imprenta Excélsior, 1948.

HURTADO, Alberto. ¿Es Chile un país Católico? Santiago: Ediciones Splendor, 1941.

JEVTIC M. Political science and religion. Politics and Religion Journal, v. 1, n. 1, p. 59-69, 2007,

KESSLER, Juan. El comienzo de los protestantes, pentecostales y adventistas en Chile. Santiago: Primeras Ediciones; Sabiduría Libros, 2019.

LABARCA, Eduardo. El Chile invadido, reportaje a la intromisión extranjera. 2. ed. Santiago: Editorial Austral, 1969.

LAGOS, Humberto. El general Pinochet y el mesianismo político. Santiago: LOM, 2001.

Crisis de la esperanza. Santiago: Presor, 1988.

LALIVE D’EPINAY, Christian. El refugio de las masas. Santiago: Ediciones El Pacífico, 1968.

LÖWY, Michael. Guerra de dioses, religión y política en América Latina. México: Siglo Veintiuno Editores, 1999.

MANSILLA, Miguel. La buena muerte. La cultura del morir en el Pentecostalismo. Santiago: UNAP-RIL, 2016.

La cruz y la esperanza: La cultura pentecostal en la primera mitad del siglo XX. Santiago: Universidad Bolivariana, 2009.

Nacidos en la calle. De la construcción bestial del predicador callejero a su construcción como patrimonio cultural. Revista de Ciencias Sociales, Santiago del Estero Argentina, 2005. Disponible en: <http://acilbuper.webcindario.com/aguero_nacidos_en_la_calle.html>. 
MANSILLA, Miguel; ORELLANA, Luis. El Obispo Durán y la jaula de hierro. Santiago: Le Monde Diplomatique, p. 8, Jun. 2019.

Evangélicos y política en Chile 1960-1990. Santiago: RIL Editores; Universidad Arturo Prat, 2018.

MANSILLA, Miguel; ORELLANA, Luis; PANOTTO, Nicolás. La participación política de los evangélicos en Chile (1999-2017). Rupturas, v. 9, n. 1, p.179-208, 2019.

ORELLANA, Luis. El fuego y la nieve, historia del movimiento pentecostal en Chile 1909-1932. Concepción: Ceep Ediciones, 2008.

ORTIZ, Juan. Historia de los evangélicos en Chile 1810-1891: de disidentes a canutos. Concepción, Ceep Ediciones, 2009.

PALMA, Irma (Ed.). En tierra extraña. Itinerario del pueblo pentecostal chileno. Santiago: Editorial Amerindia, 1988.

PARKER, Cristian. Religión y posmodernidad. Lima: Proceso Kairos, 1997.

. La otra lógica en América Latina: religión popular y modernización capitalista. México: FCE, 1996.

PÉREZ DE ARCE, Hermógenes. Historia de la revolución militar chilena 1973-1990. Santiago: Editorial El Roble, 2018.

PÉREZ, José. Entre Dios y el César, el impacto político de los evangélicos en el Perú y América Latina. Lima: Konrad Adenauer Stiftung, 2017.

PIÑERA, Bernardino. La Iglesia chilena en medio de las corrientes ideológicas actuales. Pastoral Popular, n. 66, p. 2- 14, Santiago, 1961.

PUENTE, Pedro. Posición evangélica: un documento que define posiciones. Santiago: Editora Nacional Gabriela Mistral, 1975.

SÁNCHEZ, Marcial; MORENO, Rodrigo. Historia de la Iglesia en Chile. Tomo V, "Conflictos y esperanza, remando mar adentro". Santiago: Editorial Universitaria, 2017. SEPÚLVEDA, Juan. De peregrinos a ciudadanos. Santiago: CTE-Konrad Adenauer Stiftung, 1999.

Editorial. Evangelio y Sociedad, n. 7, p. 2, 1990.

STOLL, David. ¿América Latina se vuelve protestante? Cayombe, Ec: Abya-Yala, 1991. 
SVENSSON, Manfred. Que al Tedeum se lo lleve el cuco. Prensa Evangélica, n. 125, p. 12, 2012.

TELEVISIÓN NACIONAL DE CHILE. Reportaje, 12 Set. 1988.

TENNEKES, Hans. El movimiento pentecostal en la sociedad chilena. Iquique, CL: CIRN, 1985.

TOCQUEVILLE, Alexis. La democracia en América. México: FCE, 2012.

VERGARA. Ignacio. El protestantismo en Chile. Santiago: Ediciones del Pacífico, 1962.

VIDAL, Rodrigo. Entender el templo pentecostal, elementos, fundamentos, significados. Concepción: Ceep Ediciones, 2012.

WILLEMS, Emil. Followers of the new faith. Culture change and the rise of protestantism in Brasil and Chile. Nashville. TN: Vanderbit University Press, 1967.

ZELADA, Ernesto. Vea, p. 15, 16 Out. 1975.

Revistas:

Capítulo 30.“División en el pueblo evangélico. Año VI, p. 10-11, Oct. 2000.

Chile Pentecostal. Órgano oficial de la Iglesia Metodista Pentecostal de Chile hasta 1979.

n. 606, p. 5, 1975. Conferencia Anual de la Iglesia Metodista Pentecostal de Chile Argentina y Perú.

La Voz Pentecostal, Órgano oficial de la Iglesia Metodista Pentecostal de Chile desde 1980.

CNI infiltró Iglesia Metodista Pentecostal, Punto Final, p. 11, Nov. 1991.

Periódicos:

El Mercurio. Candidatos a la conquista del voto evangélico, 29 Set. 1999.

La Tercera. Santiago, septiembre 15 de 1975.

Santiago, 17 Set. 1984.

Santiago, 18 Set. 1988.

Santiago, 18 Set. 1989. 
. Santiago, 17 Set. 1990.

. Cisma amenaza a la Iglesia Metodista. Segundo cuerpo, p. 1-3, 24 Fev. 1991.

La Época. Santiago, 17 Set. 1990.

Vea. Monseñor Carlos Camus, La polémica de sobre mesa, p. 10-13. 16 Out. 1975.

Vistazo. Periódico de orientación marxista que reporto las acusaciones de corrupción compromisos políticos del Obispo Umaña en sus ediciones de los días 10, 17, 24 y 31 de diciembre de 1963.

. Ediciones de los días 10, 17, 24 y 31. Santiago, Dic. 1963.

Capitulo 30. División en el pueblo evangélico por causas políticas, n. 76, p. 10-11, Set. 2000.

Digital

Constitución política de chile del 1980. Disponible en: <https://www.bcn.cl/historiapolitica/constituciones/detalle_constitucion?handle=10221.1/60446, consultado el 24.06.2020>.

Noticiero 60 minutos. TVN, 14 Set. 1975. Disponible en: <https://www.youtube.com/watch?v=NIEabt1caRc\&fbclid=IwAR1zMUMnzVB7qH-TMED0tsLTSgSK2UgLjWNOfXOwaEAtJ6H8QcXwy9rJUIA>.

Te Deum Evangélico, Set. 1988: <https://www.youtube.com/watch?v=aPN1MGlj_ $w g \& t=29 s>$. 